\title{
Rules of Redistribution and Foreign Aid: A Proposal for a Change in the Rules Governing Eligibility for Foreign Aid
}

\begin{abstract}
Branko Milanovic*
When income is redistributed at national level, the minimum requirement is that the transfers should be progressive, that is flow from richer to poorer individuals. The same rule should hold at the global level: it is not sufficient that transfers be from a richer to a poorer country. But normally we do not know who are the taxpayers who finance international aid nor who are the beneficiaries of aid. We can nevertheless establish the rules such that the likelihood of a globally regressive transfer is minimized. This implies taking into account countries' national income distributions: penalizing countries with highly unequal distributions since there exists a non-trivial probability that the transfers may be received by people richer than rich countries' taxpayers. Some rules for changing eligibility criteria for aid are proposed.

JEL classifications: $F_{35}, D_{3}$

Keywords: aid, redistribution, global income distribution
\end{abstract}

\section{The Rules of Redistribution at the Global Level}

At the national level, social transfers have two functions: one is social insurance and income smoothing as is the case with insurance for the old age (pensions) or unemployment. An-

* World Bank and Carnegie Endowment for International Peace, Washington. I am grateful to Sanjay Reddy, Thomas Pogge, Leif Wenar, an anonymous referee, and the participants of the conference »Equality and the New Global Order « held at JFK School of Government at Harvard (May II-I3, 2006) for helpful comments. The views expressed here are author's only and should not be attributed to the organizations with which he is affiliated.

Correspondence Address:

Branko Milanovic, World Bank, Room MC 3-559, I818 H Street NW, Washington D.C. 20433, USA, e-mail: bmilanovic@worldbank.org

Received I5 Nov 2007, accepted 2I Jan 2008

(C) INTERVENTION 5 (I), 2008, I89-205 
other function is purely redistributive: to help, without any direct quid pro quo, the poorest members of the society. These are social assistance or welfare transfers. For welfare transfers, a general and minimum requirement is that they be pro-poor or progressive. This means that they should transfer money from richer to poorer households. Otherwise, the whole function of poverty alleviation would be negated if the poor were to transfer money to those who are better off than themselves.

When we move to the global level, the first function of social transfers, insurance, cannot exist because it requires the existence of a government that collects taxes and social security contributions and then disburses them later to those who have contributed. However, the second function - social assistance, that is, transfer of funds according to need only - does exist even if its size is modest. These transfers take two forms: bilateral grants or aid given by the governments of the rich countries (mostly OECD countries) to the governments or private entities in poor countries; and soft loans disbursed by international financial institutions. These loans, like e. g. those of the World Bank-affiliated International Development Agency (IDA), carry minimal interest rates and long maturities. Hence the subsidy element is substantial and the "appellation " of aid is appropriate. ${ }^{.}$

Now, it is not unreasonable to require that international social assistance should follow the same rules as national social assistance: transfers need to flow from the rich to the poor, i. e. to be progressive. (Of course, we take it as given here that some international transfers do exist. But what are exactly the "obligations" of rich countries toward the poor, and whether they really exist at all, is an object of wide-ranging discussion. In a recent paper, Conybeare [2007] presents a nice summary of the debate on global distributive justice.) It is often thought that the very fact that they flow from a rich to a poor country is sufficient for this. But this is not the case, for it does not take into account income distributions in the two countries. ${ }^{2}$ The transfers are in reality taxes paid by the residents of rich countries and received by the residents of poor countries. But we cannot be sure that the average tax payer in a rich country is richer than the average beneficiary in a poor country. And indeed it is often argued in the popular press that some of the international transfers end up lining up the pockets of rich people in poor countries. Then the questions can legitimately be asked: why should relatively poor people in rich countries transfer money to the rich people in poor countries? And indeed such transfers would be globally regressive.

International transfers have also domestic implications. Consider the following situation. Let the taxpayer in the rich country be relatively poor (within that country) while still richer than the beneficiary in the poor country. Thus, while the transfer will be globally progressive, it will, on the other hand, increase inequality in the rich country (the poor in the rich country will now be worse off compared to the rich). Moreover, to continue with the

I This is not the case with (say) loans from the International Monetary Fund (IMF) which carry an almost market rate of interest and have a very small element of concessionality. Nor with the bulk of World Bank (as opposed to IDA) loans.

2 "Income distribution « here and in the rest of the text means either distribution of income or distribution of consumption. 
same example, let the recipient in the poor country be relatively rich - compared to other people in his/her country. Then the transfer would worsen the national income distribution in the poor country as well. Graphically, this is the situation depicted in figure I where the taxpayer's income is denoted by $T_{1}$, and the beneficiary's income by $B_{1}$.

\section{Figure I: Progressive Transfer at the World Level and Worsening National Income Distributions}

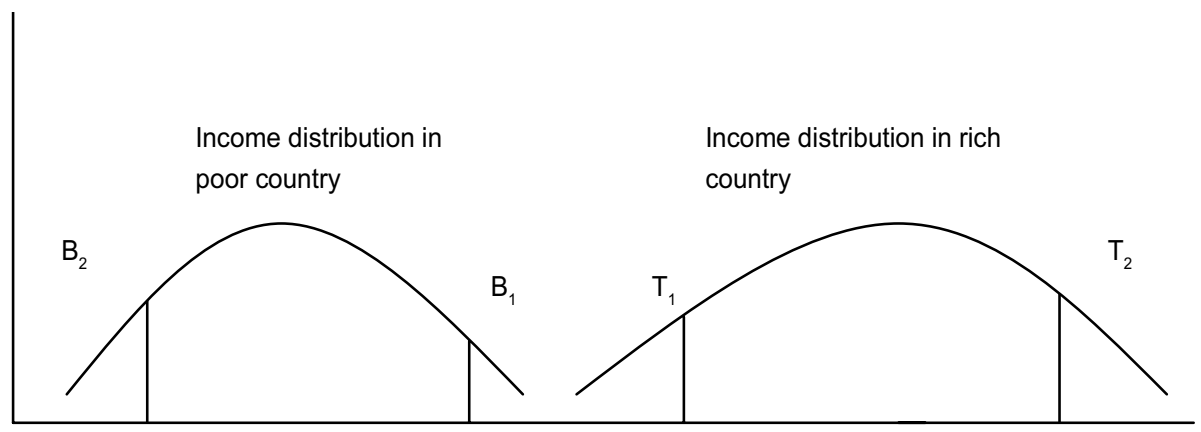

Income

This type of transfers is also shown in table I (p. 192) in the first column. Table I shows different possibilities which exist depending on the relative position of rich countries' tax payers and poor countries' beneficiaries. There are eight of them. Note first that in all cases, aid will reduce the difference between mean incomes of the two countries. This can be called Progressivity I. But only when the taxpayer $\mathrm{T}$ is better off than the beneficiary $\mathrm{B}$ will there be global progressivity: the transfer will reduce global income inequality. ${ }^{3}$ Therefore all transfer types five through eight are »eliminated « as undesirable since they would worsen global income distribution.

But even if we satisfy these two progressivities (global and Progressivity I), it does not follow that transfers will be as desirable and efficient as they should be. Moreover, they may not be politically sustainable if they lead to increased inequalities in both countries, or in either of them. This is the case for transfer types one through three. In the end, only transfer type four will satisfy all the desiderata. It will reduce mean income differences between the countries, and improve global as well as national income distributions. ${ }^{4}$ This is the transfer which goes from a rich individual (taxpayer) in the rich country to a poor individual (beneficiary) in a poor country. It is depicted by positions $\mathrm{T}_{2}$ and $\mathrm{B}_{2}$ in figure $\mathrm{I}$.

3 We assume throughout, as is standard, that the transfer is not so large that it reverses the relative positions of the two individuals involved. Thus, if $\mathrm{T}>\mathrm{B}$ before the transfer, it remains so after the transfer.

4 "Improvement of distribution« is used here and below to mean "reduction in inequality«. It is, of course, a non-technical use: in a welfare sense, a reduction in income inequality will translate into welfare improvements only under specific conditions (e.g., the same and additive individual utility functions). 


\section{Table I: Different Types of Transfers (I to 8) and Their Effect on Global and National Income Distributions}

\begin{tabular}{llllll}
\hline & \multicolumn{5}{c}{ T better off than B } \\
\hline Transfer type & 1 & 2 & 3 & 4 \\
\hline Taxpayer's (T) position in rich country & Poor & Poor & Rich & Rich \\
Beneficiary's (B) position in poor country & Rich & Poor & Rich & Poor \\
Distribution in rich country & Worse & Worse & Better & Better \\
Distribution in poor country & Worse & Better & Worse & Better \\
World distribution of income (among persons) & Better & Better & Better & Better \\
$\begin{array}{llllll}\text { Difference in mean incomes between rich } \\
\text { and poor country (Progressivity 1) }\end{array}$ & Reduced & Reduced & Reduced & Reduced \\
\hline
\end{tabular}

T worse off than B

\begin{tabular}{lllll}
\hline Transfer type & 5 & 6 & 7 & 8 \\
\hline Taxpayer's (T) position in rich country & Poor & Poor & Rich & Rich \\
Beneficiary's (B) position in poor country & Rich & Poor & Rich & Poor \\
Distribution in rich country & Worse & Worse & Better & Better \\
Distribution in poor country & Worse & Better & Worse & Better \\
\hline $\begin{array}{lllll}\text { World distribution of income (among persons) } \\
\text { Difference in mean incomes between rich }\end{array}$ & Worse & Worse & Worse & Worse \\
and poor country (Progressivity 1) & Reduced & Reduced & Reduced & Reduced \\
\hline
\end{tabular}

\section{How to Formalize the Rules?}

To define the "best" possible transfer we need to deal with two parts of the issue, that is, we need to "locate " the taxpayer and the beneficiary in their national as well as in the global distributions. The latter is especially important since it allows us to situate the beneficiary vis-à-vis the taxpayer. This is all the more important since the calls to improve the efficiency of aid deal precisely with this part of the problem: how to avoid the situation where the beneficiaries are rich people in poor countries who are better off than the taxpayers who finance the transfer. An obvious way to do this is to improve the quality of projects which are financed by aid, that is, to target them better on poor people in poor countries. Hence, for example, the recent emphasis on pro-poor growth. A similar role is supposed to be played by better governance in recipient countries. But while improvements in targeting and efficiency of aid are important, their results are slow to materialize, the effects of the projects are often unclear, and the agreements on who the real beneficiaries of transfers are, is elusive. If we had such information, it would be foolish not to use it. But the problem is that we normally do not have it. Yet even without such information, and on an a priori basis, we 
still should be able to say something about the ways to minimize the likelihood of globally regressive transfers. To this issue we turn next.

\section{I The Idea Illustrated: Single Randomness (Beneficiaries Are Not Known)}

We take the targeting of projects financed by aid as given, i.e., we assume that we are unable to tell a priori whether a project in one country is more likely to help the poor than a project in another country, and look at income distributions in the two countries to assess where the probability of a "wrong" (regressive) transfer will be less. ${ }^{5}$ The idea is simple: if everybody (or almost) everybody in a poor country is poorer than everybody (or almost everybody) in a rich country, then the probability of a regressive transfer will tend toward zero. In the extreme case, illustrated above in figure I, when no one in a poor country is better off than anyone in the rich country, there is no overlap of the distributions, and all transfers are progressive at the global level. To achieve global progressivity it does not then matter who $B$ is.

But the cases of complete absence of overlap are very rare. Consider a more realistic case where there is some overlap and where we have a choice between transferring some funds from the US (rich country) to either Ecuador or Egypt (poor countries). ${ }^{6}$ We choose these two countries because they have the same mean per capita income (calculated from household surveys and converted in dollars of equal purchasing power) of about US-\$ (in purchasing power parities [PPP]) I,47O. But their income distributions are quite different. ${ }^{7}$ Figure 2 (p. 194) shows mean income for each percentile of income distribution in the US, Ecuador and Egypt. ${ }^{8}$

We can easily see that people in Ecuador's top income percentile are richer than almost 60 percent of the US population, and were they to capture the benefits of aid, the likelihood of a regressive transfer would be high. (The likelihood would still less than Ioo percent because the transfer could be financed out of the income of the richest 40 percent of US-Americans.) This is in contrast to the situation of Egypt where the top percentile's income is higher than income of only 37 percent of US-Americans. The likelihood of a regressive transfer still exists but is much less. Thus, if we know nothing about the quality of aid-financed programs in the two countries, we should, in principle, prefer that the funds be disbursed to Egypt because of lower likelihood of a globally regressive transfer.

5 Equivalently, Bourguignon et al. (2006) in their simulation of the effect of aid on international (not global) distribution of income assume that effects of aid are distributed equally across all fractiles of recipient country's distribution.

6 Wopczuk et al. (2005) build their case precisely on the absence of significant overlap in income distributions between poor and rich countries. They show that progressive domestic taxation will do almost nothing to reduce global inequality because such transfers do not take place between the globally rich and globally poor. The world Gini coefficient decreases by less than one percent. In order to reduce gobal inequality (and poverty) transfers have to be international.

7 The Gini coefficients are 50.7 for Ecuador and 34.3 for Egypt.

8 All the data are from the year 2002 and are expressed in 2002 dollars of equal purchasing power. 
Figure 2: Income by Percentile of Income distribution - United States, Ecuador and Egypt (Year 2002; in 2002 US-\$ of International Purchasing Parity) ${ }^{\mathrm{r}}$

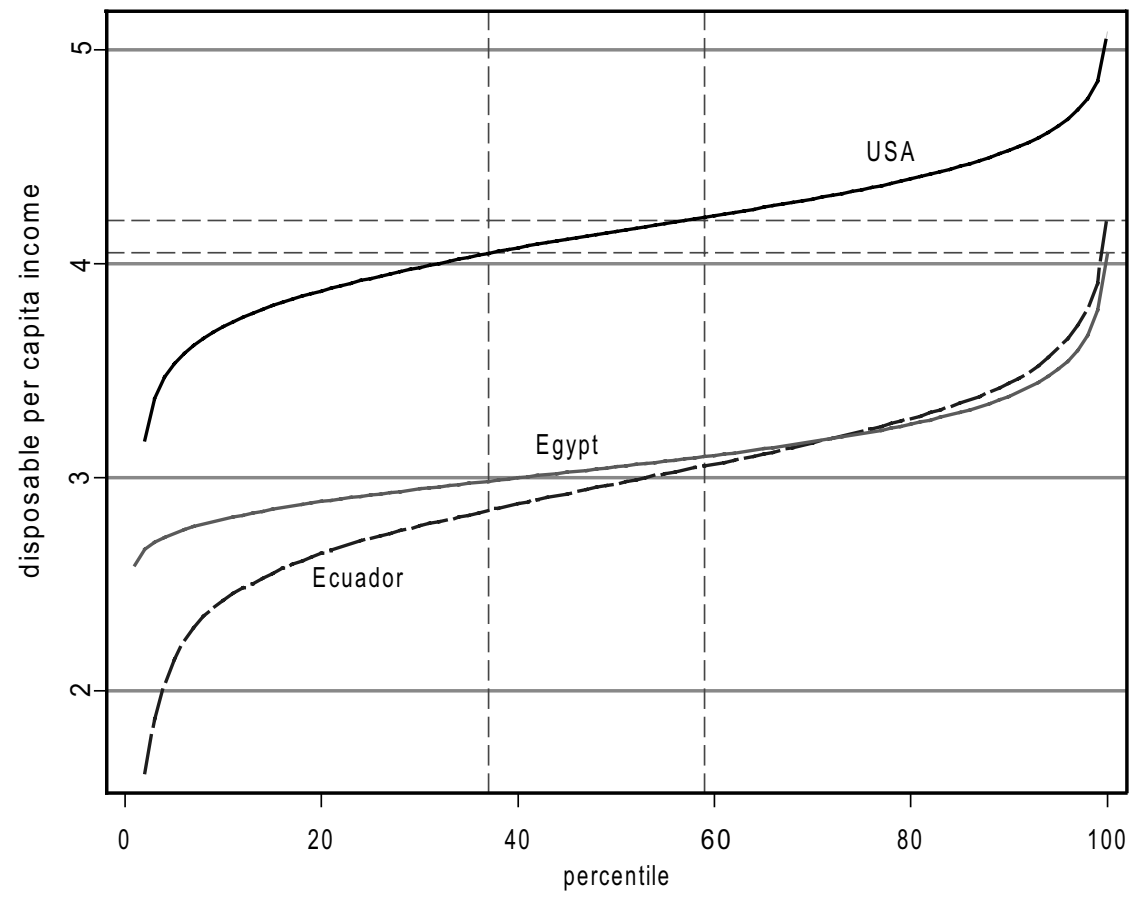

I Disposable per capita income in logs.

Source: World Bank (n.y.), own calculations

This intuition needs to be formalized because looking at the top decile alone is not sufficient. We need to look at the entire income distribution. To see why suppose that Ecuador's distribution is so extremely unequal that almost all people (say, 99 percent) have incomes that are at the subsistence level, while the top percentile's income is higher than that of the American top percentile. Then, if the distribution of benefits is random, in 99 percent of cases the transfer could still be globally progressive. Looking at the position of the top percentile only would be misleading.

To operationalize this, we shall assume (first) that the rich country's taxpayer is the person with national mean income. In the US, the mean income is US-\$ (in PPP) I8,200. Then we ask: if the distribution of benefits in Egypt and Ecuador is not known, what is the likelihood that the transfers will be globally regressive? The answer to that question is provided by the cumulative distribution functions in figure 3 .

Almost no one in Egypt enjoys the level of income equal to the US mean income (the vertical line drawn at $x=4.26$ which is $\log _{\text {го }}$ of US $-\$ 18,200$ ) while about one percent of Ecuadorians do. Behind the veil of ignorance regarding project efficiency, transfers to Egypt therefore dominate transfers to Ecuador. 
Figure 3: Cumulative Distribution Functions for the United States, Ecuador and Egypt (Year 2002; in 2002 US-\$ of International Purchasing Parity) ${ }^{\mathrm{r}}$

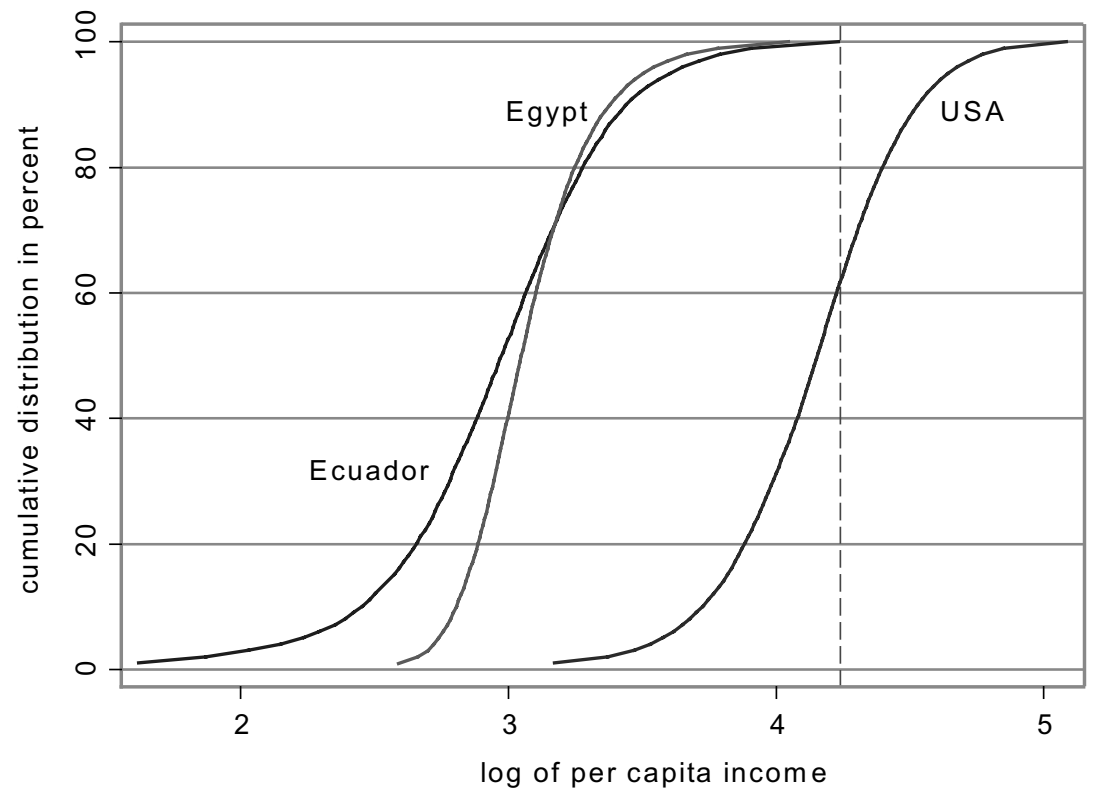

I The vertical line at the log of US-\$ I8,200 denotes US mean disposable income.

Source: World Bank (n.y.), own calculations

\subsection{Introducing Complications: Double Randomness (Neither Taxpayers Nor Beneficiaries Are Known)}

So far we had assumed that the position of the rich country's taxpayer is known, and we have looked at the randomness among recipients only. What do we know about taxpayers' incomes which would help us determine whether a transfer is progressive or not? Consider the following simple example. Line $\alpha$ in figure 4 shows the distribution of pre-tax income (gross income) amongst taxpayers in a rich country.

Curve $\beta$, which is generally steeper because of progressive tax rates, shows the distribution of taxes paid by the taxpayers. The income of the median taxpayer will be $\mathrm{M}$ but this is not what we are interested in. We are interested in the income of the person who paid the median dollar transferred to the poor country. In other words, we are interested in where the random or median dollar that financed aid came from. ${ }^{9}$ We shall call the person who paid it, the "relevant taxpayer", denoted by R. Note that the point R divides the distribution of all tax dollars into two equal halves: the area under the curve $\beta$ to the left of $\mathrm{R}$

9 The random tax dollar is the median dollar among all tax dollars when they are arranged (ranked) according to the income of the taxpayer. 
Figure 4: Taxes Paid and Gross Income: An Illustration

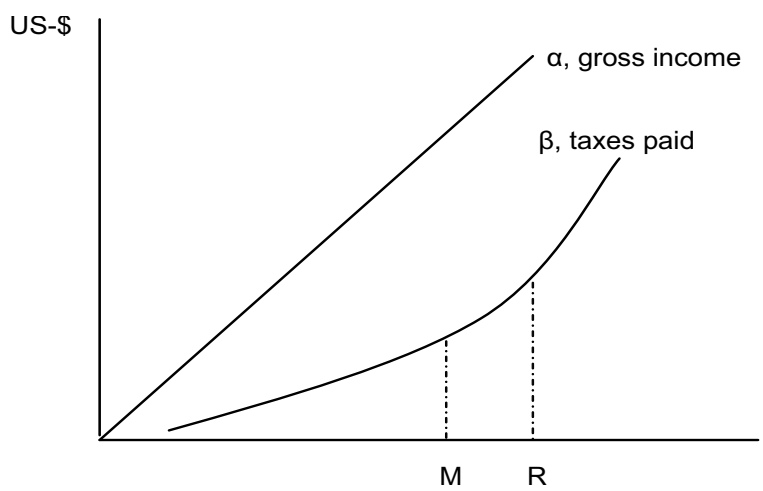

is equal to the area to the right of $\mathrm{R}$ (figure 4). The relevant taxpayer $\mathrm{R}$ must be richer than the median taxpayer $\mathrm{M}$ so long as the tax system is progressive. ${ }^{10}$

Here and below, we deal with direct taxes only. If one were to introduce indirect taxes, which are often (domestically) regressive, the convexity of the curve $\beta$ would be much less and the relevant tax payer would move to the left, i.e., will be less rich. This would tend to weaken somewhat our conclusion (see below) regarding the very low likelihood of regressive transfers between rich and poor countries. ${ }^{\text {II }}$

The richer the relevant taxpayer $\mathrm{R}$, the less the likelihood of a regressive transfer (for a given random distribution of benefits in the poor country). When will the relevant taxpayer's position move to the right? There are two simple cases. If the tax system in a rich country becomes more progressive and the pre-tax income distribution stays the same, then the relevant taxpayer will be richer. Similarly, if the underlying pre-tax income distribution in the rich country becomes more unequal, and the tax schedule remains the same, the relevant taxpayer will again become richer. In other words, with these two changes in the rich country (more progressive taxation, more unequal pre-tax distribution), the likelihood of a globally regressive transfer lessens.

We can now combine the two sides: rich and poor countries. Consider again transfers from US to Ecuador. Let us determine first the relevant taxpayer in the US. In figure 5, we show gross per capita income for each percentile in the US income distribution in the year 2000, and both direct taxes and the average effective tax rate paid. (Individuals are ranked by gross per capita income and the entire US distribution is divided into Ioo percentiles.)

Io An alternative approach to finding out the relevant taxpayer would consist in calculating the expected gross income of taxpayers where weights are given by the share of taxes paid. This can be written as $E(y)=\sum_{0}^{\max } y_{i} \frac{t_{i}}{T}$ where $y=$ gross income, $t=$ taxes paid by $i$-th taxpayers and $\mathrm{T}=$ total tax intake. Since tax rates are progressive, this alternative definition of the »relevant taxpayer " will yield a higher income than the median-based definition. I owe this alternative definition to Thomas Pogge.

II We do not introduce indiret taxes primarily because of lack of such data in the households surveys we use here. However, this could be an interesting extension to consider in future. 
Figure s: Gross Per Capita Income and Direct Per Capita Taxes Paid (Top Panel); and Effective Tax Rate (Bottom Panel), United States 2000
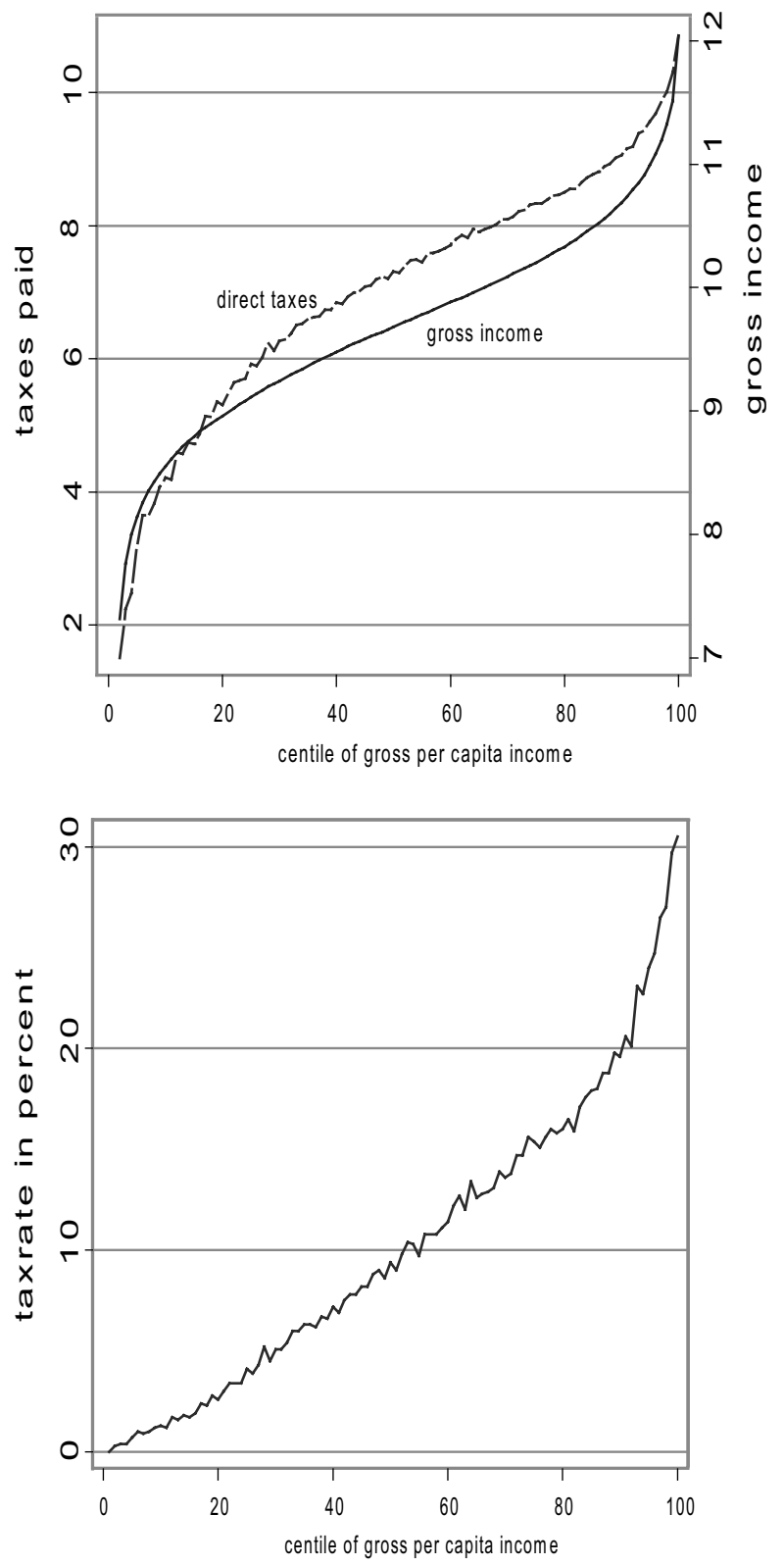

I Both direct taxes paid and gross income expressed in dollars per capita, in logs.

Source: Micro data from Luxembourg Income Study, own calculations 
The top panel shows total per capita taxes paid which, as we expect, rise faster than gross per capita income starting with the $2 \mathrm{O}^{\text {th }}$ percentile of gross income distribution. The bottom panel shows the effective tax rate which more or less increases steadily from zero percent to 30 percent.

Next, we look at the distribution of taxes paid by gross per capita income (see figure 6) and find income level such that it divides the distribution of taxes paid into two equal halves.

Figure 6: Cumulative Share of Taxes Paid and Income Per Capita, United States 2000

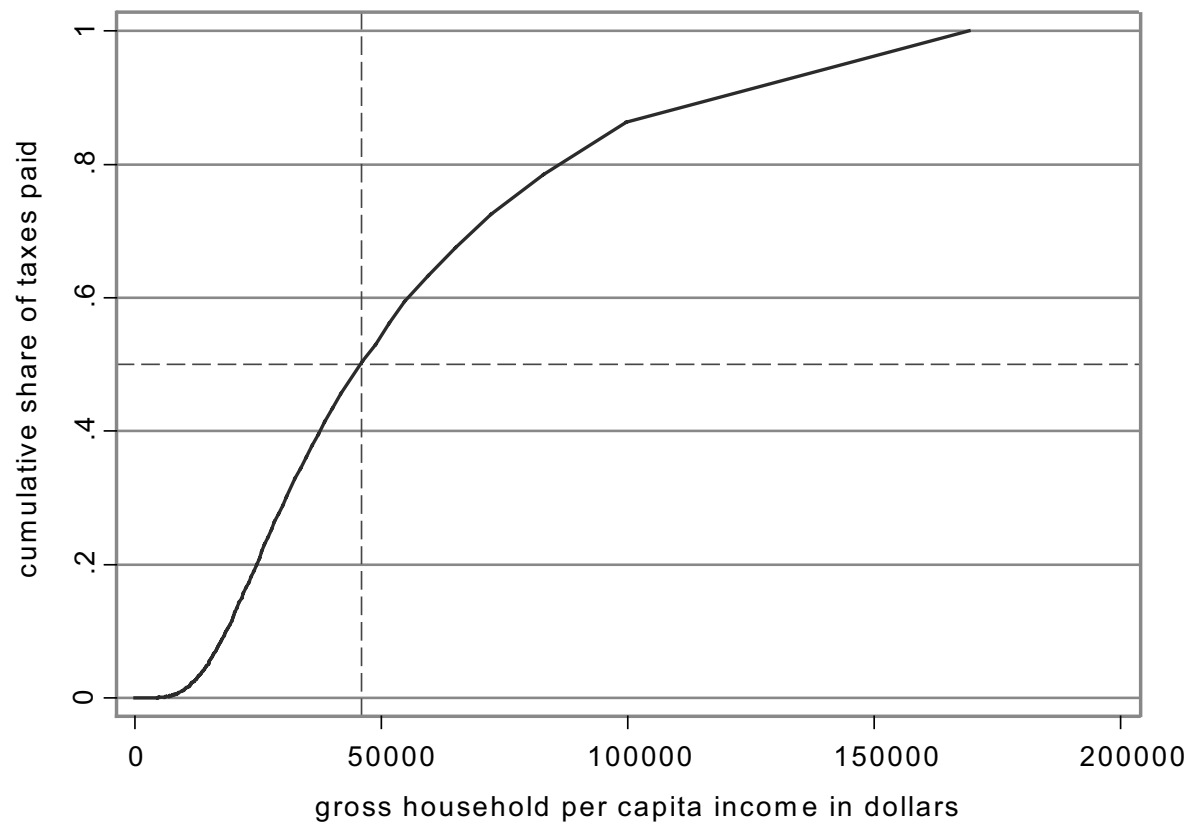

I Vertical line drawn at $\mathrm{x}=\mathrm{US}-\$ 46,000$.

Source: Micro data from Luxembourg Income Study, own calculations

This income is US-\$46,000 per person per year. In other words, it means that individuals having gross per capita household income of US-\$46,000 and less have paid exactly onehalf of all direct US taxes. The income level of the relevant taxpayer, US-\$46,00o per capita, corresponds to the $9 \mathrm{I}^{\mathrm{st}}$ percentile of US income distribution. ${ }^{\mathrm{I2}}$

I2 Using the criterion mentioned in the footnote above (mean weighted per capita gross income where weights are tax shares), the »relevant « taxpayer's income is US-\$ 63,500. It corresponds to a position between the $95^{\text {th }}$ and $96^{\text {th }}$ percentile of US income distribution. (Note that the two top percentiles in the US pay more than 2I percent of all direct taxes.) 
But to see whether this individual may be richer or poorer than a random beneficiary of foreign aid, we must look at his/her disposable income (not gross income). Disposable per capita income of people with gross per capita income of US- $\$ 46,000$ per year, is US- $\$$ 33,700 . What is then the probability, under the assumption of random distribution of benefits, that the transfer from a US taxpayer to an Ecuadorian beneficiary will be globally regressive? To find this out, we need to calculate the percentage of Ecuadorians that have an income greater than US-\$33,700 (in PPP). The answer is, less than one percent.

It may be thought that the US because of its unequal pre-tax income distribution is likely to have the relevant taxpayer situated relatively high in the income distribution, and that because of its high average level of income, the relevant taxpayer's absolute income is likely to be much higher than in other developed nations. This is partly true. To contrast it, consider the example of Sweden. The random tax dollar is paid by the taxpayer at the $77^{\text {th }}$ percentile of income distribution. The relevant taxpayer's gross per capita income is just a shade under 200,000 kronen per year, which using the 2000 PPP exchange rate of I0.09 gives a gross per capita income of about US-\$20,000 (in PPP). This is less than one-half of the relevant taxpayer's income for the US. The relevant Swedish taxpayer's disposable income is US-\$13,575 (in PPP) per capita per year. Consequently, transfers from Swedish tax payers are more likely to be globally regressive than those financed by US taxpayers. The difference however should not be exaggerated as the two last lines in table 2 make clear.

\section{Table 2: Donors and Likelihood of Regressive Transfers}

\begin{tabular}{|c|c|c|}
\hline & $\begin{array}{l}\text { United } \\
\text { States }\end{array}$ & Sweden \\
\hline Mean gross per capita income (US-\$ in PPP) & 22,502 & 15,620 \\
\hline Gini of gross per capita income & 44.7 & 31.0 \\
\hline Concentration coefficient of direct taxes ${ }^{1}$ & 67.8 & 41.7 \\
\hline Gini coefficient of disposable per capita income & 40.2 & 27.4 \\
\hline Tax rate paid by the relevant taxpayer (in percent) & 20.6 & 25.8 \\
\hline Highest effective (average) tax rate paid (in percent of gross income) & 30.5 & 38.8 \\
\hline $\begin{array}{l}\text { Position of the relevant taxpayer in gross per capita income } \\
\text { distribution (percentile) }\end{array}$ & 91 & 77 \\
\hline Gross income of the relevant taxpayer (US-\$ in \$PPP p.a; per capita) & 46,061 & 19,735 \\
\hline $\begin{array}{l}\text { Disposable income of the relevant taxpayer (US-\$PPP in PPP p.a.; } \\
\text { per capita) }\end{array}$ & 33,676 & 13,575 \\
\hline Likelihood of regressive transfer to Ecuador (in percent) & Less than 1 & Less than 2 \\
\hline Likelihood of regressive transfer to Egypt (in percent) & Quasi nil & Less than 1 \\
\hline
\end{tabular}

I Concentration coefficient of taxes paid when individuals are ranked by their per capita gross income.

Source: Micro data from Luxembourg Income Study, own calculations. Both US and Swedish surveys are for 2000 
An obvious, and important, conclusion is how small is the likelihood that transfers financed by rich countries' taxpayers may end up in the pockets of people who are richer than the taxpayers. This issue is indeed one of legitimate concerns voiced in discussions regarding equity and efficiency of foreign aid. But the calculations shown here dispel the notion that such instances are common. We have seen that even transfers that are nationally distributionally neutral, i.e., which would benefit equally the rich and poor in the recipient countries, have a quasi nil chance (between just slightly over zero percent and less than two percent) to be globally regressive. This result is, of course, the product of two strong facts of modern life. First, the existence of extremely large differences in mean incomes between rich and poor countries. Second, the existence of progressive tax systems in rich countries which ensure that the random tax dollar that finances foreign aid is contributed by very rich people, with incomes far above the country mean.

The difference among donors is, in its implications, similar to the difference among the recipient countries. Donor countries with (a) higher average income, (b) more unequal underlying (gross) income distributions, and (c) more progressive tax schedules are likely to have richer relevant taxpayers. Transfers financed by their taxpayers are less likely to be globally regressive and their contribution to global redistribution ought to be greater. To make it simple: the transfers should flow from rich and unequal societies to poor and equal societies. ${ }^{13}$

\subsection{Caveats}

In order to be clear about our »rules« it is important to note four things however.

First, this result does not depend on targeting of transfers in recipient countries.

Second, we focus on minimizing the likelihood of making a globally regressive transfer, not on maximizing the expected income distance between $\mathrm{T}$ and $\mathrm{B}$. To explain: if targeting of transfers in two recipient countries, $\mathrm{X}$ and $\mathrm{Y}$ (where $\mathrm{X}$ has a lower median and mean income), is unknown, this means that in terms of national income distributions, the income position of $\mathrm{B}$ is random. This in turn implies that, within national distributions, the expected income of B will be equal to the national median. Since X's median is less than Y's, the expected income distance between the rich country's taxpayer and a (random) beneficiary will be greater in the case of country X than Y. Yet the likelihood of a globally regressive transfer - a thing which interests us here - may still be greater for $\mathrm{X}$ than for $\mathrm{Y}$. This is illustrated in figure 7 .

I3 That societies that are, on average, richer and more unequal should finance more transfers accords with our intuition. The same cannot be said for a more progressive (domestic) taxation. However, if two countries have the same mean incomes and distributions of gross income but differ only in the level of tax progressivity, the median tax dollar from a country with a more progressive tax schedule will come from a richer individual, and will be less likely to result in a globally regressive transfer. 
Figure 7: Difference between Globally Regressive Transfers and Maximization of Likely Income Gain ${ }^{\mathrm{I}}$

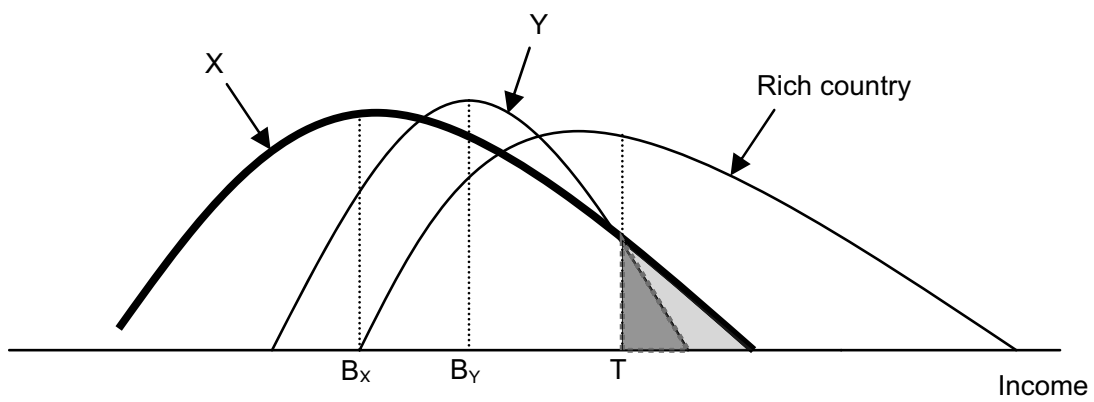

I Area under each country's curve equals I.

Note that while the distance $T_{B x}$ is greater than the distance $T_{B y}$, the area of $X$ 's income distribution to the right of $\mathrm{T}$ is greater than the area of Y's income distribution to the right of $\mathrm{T}$ (see the two shaded areas). Or, in other words, the probability of a regressive transfer will be greater for the country $\mathrm{X}$.

Third, other criteria may be introduced as, for example, the just mentioned maximization of the income distance between the taxpayer and the expected beneficiary, or maximum reduction of global poverty where only the likelihood of beneficiaries being below some poverty line matters, or maximum reduction of the poverty gap etc. But these are all secondary objectives. We believe that, as in national redistributions, the primary and the minimum objective of international aid must be that the transfers be progressive.

Fourth, the really important factor is the percentage of people in the poor country who are better off than the taxpayer in the rich country (that is, the thickness of the right tails in figure 7), not the relative position of the richest citizens of X vis-à-vis the richest citizens of Y. For example, suppose that the richest Xs are richer than richest Ys, but that both are poorer than the taxpayer who financed the transfer. Then, the likelihood of a globally regressive transfer will be zero in both cases. (And in that case, we might prefer to resort to a subsidiary objective, e.g., maximize the expected difference between $\mathrm{T}$ and B.)

The implication of the analysis so far is that the eligibility criterion, as for example for IDA lending which currently takes into account only the level of country's GDP per capita ${ }^{\mathrm{I}}$, should be complemented with an indicator of inequality. The indicator should be generally available and reasonably easy to calculate. The objective is to adjust eligibility for aid by taking into account countries' domestic levels of inequality, penalizing highly unequal countries and helping those that are not. One possibility would be to do what we have just described: focus on the thickness of the right-end tails of countries' income distributions, for example on the percentage of people with income above US-\$ 5,000 (in PPP) per year

I4 The IDA cut-off point above which a country cannot qualify for soft loans was US-\$ 865 in 2002. 
(which is about twelve times the global absolute poverty line), and calculate the probability of a regressive transfer. Another, simpler, possibility would be to adjust GDP per capita by the ratio between the mean and the median income in the country. If income distribution is very unequal, the mean-to-median ratio will be high. Thus, the inequality-corrected GDP per capita will be increased in high inequality countries which could lose eligibility for interest-free loans. ${ }^{\text {Is }}$ Consider Bangladesh and Nigeria. These two countries have approximately the same level of income, but inequality is much greater in the latter. The meanto-median ratio is I.7 in Nigeria and I.2 in Bangladesh. The introduction of inequalityadjusted income will therefore penalize Nigeria and could possibly disqualify it from receiving soft loans as long as inequality remains high.

The approach suggested here is, in one respect, directly opposite to the approach discussed by Pogge (1994). Pogge's Resource Tax would be funded from the proceeds made exploiting global exhaustible resources and would be targeted to help the poor (regardless of where they live) through the action of a facilitating agency. Now, Pogge says, consider two countries with the same per capita income but differing in that one has more poor people (because its domestic inequality is greater). Then some people might argue that more aid should be disbursed to that country (because it contains more poor). Pogge is sympathetic to this view but rejects it because it would provide a perverse incentive to the elites in poor countries not to care about the poor. ${ }^{16}$ For this reason, Pogge prefers to stick to the criterion of average income rather than to introduce the issues of domestic income distribution. Our approach would penalize the country with greater income inequality (and, as in this case, with more poor), with the rationale that a transfer to such a country is more likely to result in a globally regressive transfer than an equivalent transfer to a more equal country with the same GDP per capita. And minimization of the likelihood of globally regressive transfers is, we believe, indispensable for the system of global redistribution to be set in place and maintained. Once taxpayers begin to have doubts about it, the system is unlikely to survive.

I5 The inequality-corrected GDP per capita would be equal to the standard GDP per capita multiplied by the ratio between the mean and the median.

I6 Pogge's point that the elite may not care about the very poor is well-taken and realistic. However, other authors introduce the so-called Samaritan dilemma (expectation of aid leads potential beneficiaries to alter their behavior) that applies to the entire countries, that is, to their mean incomes. This is, in my opinion, much less reasonable. While the Samaritan dilemma might be a reasonable hypothesis when dealing with income redistribution at national level where (say) a person may prefer not to work if he is likely to get unemployment benefits, it is not a very reasonable thing to worry at international level where a country (all people in it!) cannot change its behavior in anticipation of foreign aid. The coordination problems, and lack of information how aid would be distributed (to which individuals) are just overwhelming. We thus view the concerns with Samaritan dilemma extended to the international arena and mean income of countries (as, for example, in Jansen Hagen 2006) to be far-fetched. 


\section{Possible Objections}

There are three possible objections to taking into account distribution of income when making decisions on aid. The first is a technical one: the issue of knowing what different countries' distributions are and operationalizing the idea. The second is a more fundamental one and concerns the principle of sanctions or punishment in international affairs. The third objection comes from the recent empirical findings by Chong/Gradstein (2007), which show that people in donor countries do not, in their decision to support or not aid, take into account recipient country's inequality (nor corruption). We shall deal with these objections in turn.

The technical objection is that the data on income distribution are not as easily and frequently available as GDP data. However, this is an objection whose force is surely weaker today that it was ten or 20 years ago. Major strides in the availability of income distribution data have been made recently. The data are available practically for all countries in the world, at five-yearly intervals at least. More serious is the issue of the possible incentives to temper with such data were they to be used in deciding the eligibility for aid. Although GDP data can also be falsified (and have been), it is arguably true that their deliberate falsification is more difficult since they are related to a number of other observable indicators more than income distribution. Moreover, slight changes in the definitions of income or expenditures in household surveys can produce significant changes in inequality results. Thus for example a seemingly innocuous decision as to how to value home production or how to impute rent to owner-occupied housing can result in major upward or downward revisions in inequality. What is major? In this context it means by two to three Gini points, which for most countries amounts to five to ten percent of total inequality. Arguably, it is easier to fiddle with some ten percent of inequality than with ten percent of GDP. Yet with greater independence of statistical offices and the acceptance of international standards in household surveys (plus the fact that for many poor countries that are eligible for soft loans a lot of household survey work is done by international organizations, including the World Bank), the danger of deliberate manipulation of the data can be minimized. ${ }^{17}$ Finally, the last issue of operationalization concerns what measure of inequality to take and how to relate it to the average income (GDP per capita). This needs to be pretty simple. One way to do it is, as we have suggested, to use the mean-to-median ratio.

A more fundamental issue is the one of penalization itself. The logic behind making it more difficult for countries with unequal distributions of income to qualify for soft loans is the same as the logic of international economic sanctions. They are undertaken to "punish" an elite which may lead the country in a wrong or dangerous direction; yet, in the shortterm, the sanctions often end up by punishing the population on whose account they are ostensibly implemented. Here too, we deprive a country of soft loans in order to put an additional pressure on its elite to improve income distribution - to conduct such wide-rang-

I7 One should recall that micro data from household surveys are in principle available and can be independently cross-checked. This cross-check is harder to do with national account statistics like GDP. 
ing measures as land redistribution, or to reform tax system by making it more progressive, or to improve the delivery of social programs, or to make schooling more easily accessible. But many of these programs' effects are long-term and the government that implements them may not be around to reap the benefits. Or the elite may be entrenched and oblivious of country's interests.

There are serious objections inherent in every use of sanctions in international affairs. We believe however that in this case the strength of the objections is less than in other cases. This is for two reasons. First, these are relatively mild »reprimands « for countries since they would still be part of the international community or members of the World Bank, IMF etc. Second, in no country is unequal distribution of income popular among the bulk of the population. This is almost by definition the case since unequal distribution is always to the benefit of a small minority. Sanctions would therefore create a commonality of interest between the bulk of the population and the international community, a situation very different from the politically motivated sanctions where the objectives of the "sanctioners" are often impugned. In the latter cases even beleaguered and otherwise unpopular regimes are able to harness popular support as they project themselves as protectors of the national interest. But arguing in favor of the maintenance of a very unequal distribution of income cannot, however imaginative the regime, be construed to be in some national interest, particularly not in very poor countries. Thus the popular support in the face of this type of international ostracism cannot be easily, or at all, marshaled. The power of sanctions is thereby significantly enhanced.

Chong/Gradstein (2007), using the indiviuduals' responses from the World Values Survey, find that support for aid in donor countries decreases with perceived corruption of the own government, and national income inequality, but is not affected by corruption and income inequality in recipient nations. While the first set of findings (regarding domestic variables) is obtained directly from respondents, the latter set of findings (regarding inequality and corruption in recipient nations) is obtained from country-level data on actual aid disbursement. This finding is therefore more correctly interpreted to mean that donor countries' governments do not take into account (in their bilateral aid decisions) recipient countries' corruption and income inequality - a fact which squares well with the often made claim that rich countries' governments are mostly driven in their decisions by political objectives. ${ }^{18}$ It does not address the issue of whether people in donor countries are really indifferent to see their tax dollars (or euros) go to more unequal (or corrupt) recipient countries. Actually, a lot of anecdotal evidence suggests the very opposite.

Finally, there are three positive arguments that we can adduce in favor of this proposal. First, it introduces in the international aid arena a finer, more nuanced, view regarding eligibility for aid. It basically attempts to copy to the international scene the well-accepted rules of distribution used within countries. As international aid becomes more important, there is no doubt that some rules will have to be evolved. Second, without some clear distributional rules the idea of international aid is bound to become even less popular than it 
is today. People are willing to pay taxes if they believe that the beneficiaries are poorer than themselves. They are unlikely to accept to be taxed if that assurance is absent. Third, the scheme presents a move toward world-wide awareness of inequality and the treatment of the world as a single whole.

\section{References}

Alesina, Alberto/ Dollar, David (1998): Who Gives Aid to Whom and Why?, National Bureau of Economic Research Working Paper, No. 66I2

Bourguignon, François/Levin, Victoria/Rosenblatt, David (2006): Global Redistribution of Income, World Bank Policy Research Working Paper, No. 396I

Chong, Alberto/Gradstein, Mark (2007): What Determines Foreign Aid? The Donors' Perspective, in: Journal of Development Economics (forthcoming)

Conybeare, John A.C. (2007): Efficiency, Entitlements and Deservingness: Perspectives on International Distributive Justice, in: Review of International Political Economy, Vol. I4, No.3, pp. 389-4II

Jansen Hagen, Rune (2006): Samaritan Agents? On the Strategic Delegation of Aid Policy, in: Journal of Development Economics, Vol.79, pp. 249-263

Pogge, Thomas (1994): An Egalitarian Law of Peoples, in: Philosophy and Public Affairs, Vol. 23, No.3, pp. 195-224

Wopczuk, Wojciech/Slemrod, Joel/Yitzhak, Shlomo (2005): The Limitations of Decentralized Redistribution: An Optimal Tax Approach, in: European Economic Review, Vol.49, pp. I05I-IO79

World Bank (n.y.): World Income Distribution Data, URL: http://econ.worldbank.org/projects/ inequality 
